\title{
CORRECTION
}

\section{Correction: Stepwise interventions for improving hand hygiene compliance in a level 3 academic neonatal intensive care unit in north India}

Shridhar Gopalakrishnan (D), Suman Chaurasia (D), M. J. Sankar (iD, V. K. Paul, A. K. Deorari, M. Joshi and R. Agarwal (iD)

(c) The Author(s), under exclusive licence to Springer Nature America, Inc. 2021

Journal of Perinatology (2021) 41:2847; https://doi.org/10.1038/s41372-021-01224-1

Correction to: Journal of Perinatology https://doi.org/10.1038/ s41372-021-01141-3, published online 28 July 2021
The original online version of this article was revised. The specification "These authors contributed equally" was corrected. 